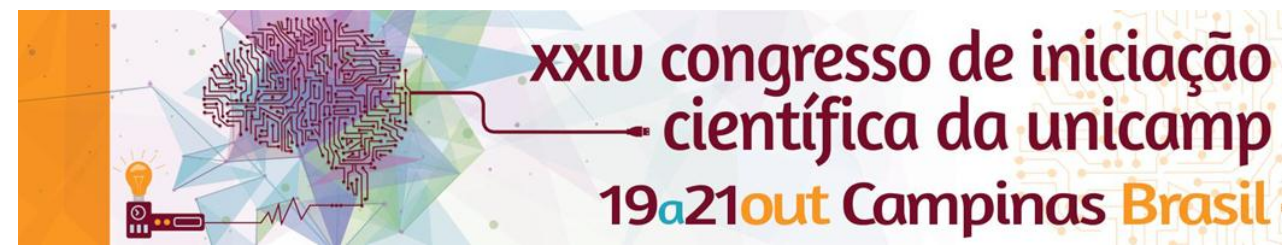

\title{
Desenvolvimento de uma ferramenta para projetos de biorrefinarias em plataforma web (módulo 2 - florestas)
}

\author{
Henrique C. de A. Venturelli, Daniel de C. Assumpção, Guilherme C. Q. Pereira, Heiko Hornung, Adriano P. \\ Mariano
}

\section{Resumo}

Esse projeto teve como objetivo o desenvolvimento conceitual de uma ferramenta em plataforma web para projetos de biorrefinarias florestais. A ferramenta auxiliará engenheiros do setor florestal, consultorias e estudantes na triagem rápida e preliminar de projetos conceituais de biorrefinarias.

Palavras-chave:

Fabrica Kraft, Biorrefinaria, Projetos Preliminares

\section{Introdução}

A biorrefinaria é uma unidade que integra processos de conversão de biomassa para a produção de combustíveis, energia e químicos. No Brasil, o setor florestal possui notável interesse na instalação de biorrefinarias, cujos projetos envolvem a orquestração de diferentes competências, como a minimização dos riscos econômicos, técnicos e de mercado, e a escolha da fração de biomassa a ser utilizada.

O objetivo desse projeto é o de disponibilizar a engenheiros de empresas do setor florestal, consultorias, e estudantes uma ferramenta web, onde o usuário seja capaz de simular, por meio de diagramas de blocos, projetos de biorrefinarias de indústrias de papel e celulose, incluindo: rendimentos mássicos e energéticos da fábrica, caracterização composicional da matéria prima florestal (madeira, resíduos florestais) e uma análise técnico-econômica a respeito das opções de biorrefinarias do setor florestal.

\section{Resultados e Discussão}

A simulação dos balanços materiais e energéticos de biorrefinarias de indústrias kraft de papel e celulose, realizada em Excel, basearam-se, respectivamente, em rendimentos mássicos e balanços termodinâmicos. A metodologia adotada para tal simulação está esquematicamente representada pela Figura 1.

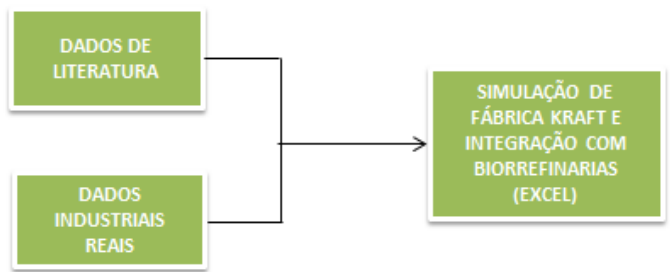

Figura 1. Metodologia utilizada no projeto.

Elaborou-se uma estrutura de diagramas de blocos, que permitirá ao usuário da ferramenta uma fácil interpretação do processo kraft de produção de papel e celulose e de suas biorrefinarias, cuja interação está representada, sob um ponto de vista geral, pela Figura 2.

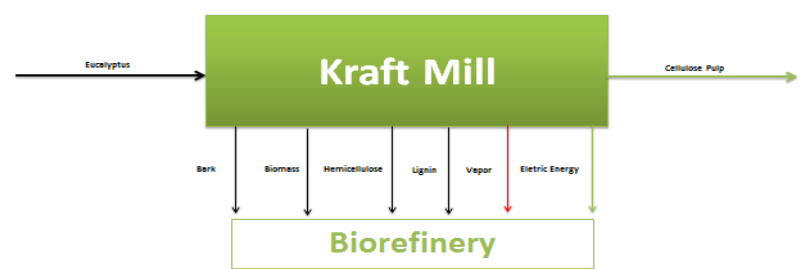

Figura 2. Representação global do processo por diagrama de blocos.

De acordo com os dados de entrada fornecidos pelo usuário, a ferramenta disponibilizará os valores de saída condizentes. A Tabela 1 ilustra os impactos na geração de vapor de uma planta kraft causados pelos desvios de $10 \%$ do conteúdo disponível de algumas biomassas para processos de biorrefinarias em relação ao caso-base, no qual não há biorrefinarias acopladas à indústria: quanto menor a geração de vapor, menor será a produção de energia elétrica para o processo Kraft.

Tabela 1. Comparação do impacto na geração de energia na usina Kraft causada por desvios de algumas biomassas.

\begin{tabular}{|c|c|c|c|}
\hline Caso-Base & Lignina & Hemicelulose & Casca \\
\hline $824 \mathrm{t} / \mathrm{h}$ & $779 \mathrm{t} / \mathrm{h}$ & $807 \mathrm{t} / \mathrm{h}$ & $818 \mathrm{t} / \mathrm{h}$ \\
\hline
\end{tabular}

\section{Conclusão}

A despeito da ferramenta em ambiente web ainda estar em seu processo inicial de construção, as simulações em excel realizadas permitem discutir, do ponto de vista de rendimentos mássicos e energéticos, diferentes cenários de biorrefinarias do setor florestal. As funções de análise técnico-econômica da ferramenta serão implementadas no decorrer da continuação do projeto.

\section{Agradecimentos}

Ao CNPQ e ao PIBIC pela oportunidade da bolsa de iniciação científica.

Mariano, A.P; Harlin, A.; Manninen, J.; Chambost, V. e Stuart, P. Techno economic analysis of process alternatives for the production of ethylenepropylene rubber from forest-based feedstocks. Tappi Journal, 2013, 12, 19-32.

Martinez, A. C. e Nakamura, I. L. A. Estudo da Integração de uma Biorrefinaria Florestal em uma Indústria de Celulose. Trabalho de conclusão de curso (POLIUSP), 2014. 